\title{
The changes in the UV emission lines of RR Telescopii from 1978 to $1993^{\star, \star \star}$
}

\section{The IUE SWP region}

\author{
R. Zuccolo ${ }^{1}$, P. Selvelli ${ }^{2}$, and M. Hack ${ }^{1}$ \\ 1 Università di Trieste, Dipartimento di Astronomia, Via G. Tiepolo 11, I-34131 Trieste, Italy \\ 2 C.N.R.- G.N.A., Osservatorio Astronomico di Trieste, via G. B. Tiepolo 11, I-34131 Trieste, Italy
}

Received October 10; accepted December 3, 1996

\begin{abstract}
Line emission intensities and FWHMs in the range 1175 - $1900 \AA$ have been measured on high resolution IUE spectra of RR Tel taken from 1978 to 1993. The variations observed in the emission line intensities show a rather strong correlation with the line ionization. The decrease is of a factor larger than three and up to ten for the low-ionization lines, and of a factor between two and three for the medium-high ionization lines. Instead, the high ionization lines have generally maintained their 1978 strength or have even increased it. For all lines no variation in the FWHM has been detected. Special attention has been paid to a very long exposure spectrum already studied by other authors for which we present new identifications and several comments. The presence of spurious emission features and camera artifacts is discussed.
\end{abstract}

Key words: stars: individual: $R R T e l$ - stars: novae, cataclysmic variables - line: identification ultraviolet: stars

\section{Introduction}

The symbiotic nova $\mathrm{RR}$ Tel is an extraordinary object on account of the richness of its emission line spectrum and of the extremely slow spectral development after the outburst that took place in 1944 (Thackeray 1977). These characteristics have made it an ideal laboratory for studies

Send offprint requests to: P.L. Selvelli

e-mail: Selvelli@oat.trieste.it

* Based on observations with the International Ultraviolet Explorer (IUE) retrieved from the VILSPA data-bank.

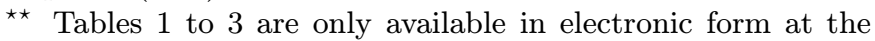
CDS via anonymous ftp to cdsarc.u-strasbg.fr (130.79.128.5) or via http://cdsweb.u-strasbg.fr/Abstract.html of astrophysical spectroscopy and for the application of the methods of diagnostics for astrophysical plasmas.

The IUE spectrum of RR Tel has been extensively studied by Penston et al. (1983) and by Hayes \& Nussbaumer (1986) but the limited time coverage in the data which were then available prevented any possible study on the long-time variations in the intensities and profiles of the UV emission lines.

More recently, Doscheck \& Feibelman (1993), hereinafter DF, have improved the list of the line intensities and identifications from a study centered on a SW spectrum with very long exposure ( $820 \mathrm{~min})$ taken in June 1983, while Aufdenberg (1993), hereinafter ADB, has combined the data from this same spectrum together with other archival data to produce a composite spectrum. Very recently, Espey et al. (1995) have presented far UV data $(900-1800 \AA)$ taken with HUT on March 1995 during the Astro-2 mission.

With the purpose of completing these previous investigations with a specific study on the behavior of the emission lines over a longer time-scale we have measured the emission intensities and the FWHMs in the IUE spectra of RR Tel taken from 1978 to 1993. In this article we list the line measurements for the spectra obtained with the SWP camera $(1175-1950 \AA)$, together with some comments and a short description of the most outstanding variations. The measurements and comments for the LW cameras $(1950-3200 \AA)$ will be reported in a forthcoming article.

\section{Observations and measurements}

We have retrieved all the IUE high-resolution spectra taken between 1978 and 1993 from the IUE VILSPA databank. We have however disregarded some spectra taken with quite short exposures in which the signal was good for a few lines only. For every year, the numbers of SWP spectra used and the corresponding exposure times are 
reported on the top of Table 1 . We have employed the standard procedures for spectral analysis contained in the ESO Midas package to measure wavelengths, FWHMs and emission intensities. We recall (Turnrose \& Thompson 1984) that the final error in the wavelength measurement of a given spectral feature in various IUE spectra is a combination of various errors due to a number of intrinsic and extrinsic factors and is on the order of $0.04-0.05 \AA$ around the mean value although the uncertainty in the positioning of the target in the large aperture can produce larger errors. The ability to centroid a spectral feature in the spectrum is also a limitation to the accuracy of the assigned wavelengths. The spectral resolution in the IUE high resolution mode, as indicated by the FWHM values of the Pt-Ne calibration spectra, varies from about $0.10 \AA$ at $\lambda=1300$ to $0.19 \AA$ at $\lambda=2000 \AA$ in the SWP camera. For an isolated narrow feature the best estimate of the measurement accuracy is on the order of one tenth of the instrumental resolution, that is on the order of $0.02 \AA$, but in many cases the spectral data are not of sufficient quality to approach this limit and slightly larger errors are found.

In our measurements we have found a confirmation for these results, and only small differences, on the order of a few hundreds of an Angstrom, have been found in the wavelength determination for the same feature in different spectra. This confirms the result by Penston et al. (1983) of a rms scatter on the order of $0.05 \AA$ of the line wavelengths about their laboratory value. For this reason and for sake of simplicity we have reported in Table 1 only one value (the average) for $\lambda_{\text {obs }}$ for each set of spectra. Needless to say, $\lambda_{\text {obs }}$ gives the wavelength value as directly measured on the spectrum, not corrected for the radial velocity of RR Tel relative to the Sun, that has a value close to $-62 \mathrm{~km} \mathrm{~s}^{-1}$ (Thackeray 1977). Instead, note that both $\lambda_{\text {meas }}$ in Penston et al. (1983) and $\lambda_{\text {rest }}$ in ADB are already corrected for the star radial velocity. We recall that the corrections for the earth and satellite motions, and therefore the reduction to an heliocentric frame of reference, are made during the image processing procedure. As customary, the wavelengths listed in the SWP spectra are vacuum wavelengths.

The spectra have been calibrated using the recent high dispersion absolute calibration of Cassatella et al. (1994) and have been corrected for a reddening value $E(B-V)=$ 0.09 using the curve of Mathis (1990). This correction is very close to that employed in other studies.

One of the main shortcoming in the observations of emission line objects with IUE is the limited dynamic range in the response of the IUE cameras which leads easily to saturation effects even at exposure levels rather low as compared with the BKG. As a consequence it is generally necessary to employ spectra taken with different exposure times in order to obtain an optimal emission line spectrum. We have carefully checked the line quality for the presence of saturation effects and for any flag associated with data points corrupted by cosmic ray events.

Only spectra taken with the large aperture have been used in order to provide reliable measurements of the emission intensities: in spectra taken with the small aperture the throughput is on the order of 50 percent on the average but the scatter is quite large.

The emission intensities have not been corrected for the degradation in the sensitivity with time of the SWP camera. The reason is that the most recent information (Garhart 1992) comes from a study based on low resolution data in three limited spectral ranges that do not fully cover the whole SWP region. These data show, however, that there is an average total degradation close to 10 percent for the time interval $1978-1992$, with a maximum of 12 percent in the $1225-1375 \AA$ range. These values are close to the photometric accuracy of IUE which is on the order of 10 percent.

\section{The spectral artifacts and other false emissions}

It is well known that IUE spectra taken with long exposures are affected by two kinds of spurious features that mimic emission lines. The so called spectral "artifacts" appear in the same location on every long exposure spectrum and are due to camera phosphorescence (Crenshaw et al. 1990). They are rather sharp and their intensity generally increases with the exposure time. The other pseudoemission features (blemishes) are instead associated with single events such as cosmic-ray hits and are generally very sharp. The long exposure spectrum of RR Tel (SWP $20246-820 \mathrm{~min}$ ) is contaminated by both these features. A list of the former is given in $\mathrm{ADB}$.

We have checked this list by comparing the same SWP 20246 spectrum with a long exposure high resolution spectrum (SWP 6325) of the cataclysmic variable $\mathrm{V} 603$ Aql that is characterized by an almost featureless continuum with only a few very wide over-imposed emission lines. This makes rather easy to identify the spectral artifacts as those "emission" features which are common to the two spectra. We confirm several of the artifacts found by ADB and we list them in Table 3a but we remark that in many other cases their presence is questionable. It is worth pointing out, however, that some caution should be taken in this context because some aspects related to the "artifacts" presence itself, the repeatibility of such features in different spectra, and the scaling of their intensities with the exposure time seem still unclear (Selvelli et al. 1997).

Incidentally, in this study we have also found clear evidence of several new pseudo-emission features that are common to the two spectra and therefore may be considered as additional spectral artifacts. They are listed in Table 3b.

Another source of pseudo emission features in IUE high resolution spectra of emission line objects is the 
over-spilling of strong, saturated emission lines that may affect the adjacent order in the echelle spectrum, especially in the range $1175-1300 \AA$ where the separation between adjacent orders is quite small. We attribute to this mechanism the two emissions at $\lambda 1227.8$ and $\lambda 1231.6$ identified as NI in ADB. In our opinion these features are produced by overspilling of the NV doublet at $\lambda 1238.82$ and $\lambda 1242.81$. This is supported by the fact that the observed separation between the two pairs of lines is the same, $4.0 \AA$, in contrast with the separation between the laboratory values of the NI lines which is $3.79 \AA$. Also, the continuum level in the region $\lambda \lambda 1225-1231$ is below zero, another IUE "artifact" produced by the subtraction of an excess of inter-order background, caused by the overspilling of signal from the successive order (that of the NV lines, where a wide emission is also present). Another pseudo-emission feature in the same SWP 20246 spectrum is observed at $1207.5 \AA$ and is produced by overspilling of the OV $\lambda 1218.35$ line in the successive order, while the feature at $1205.7 \AA$ is associated with the geo-coronal Ly $\alpha$ line filling the small aperture.

\section{The tables}

About 110 emission lines are present in the SW spectrum of RR Tel, shortward of $1900 \AA$ (several of them being present in the 1983 long exposure spectrum SWP 20246 only). For all the unsaturated lines the FWHM values (in $\AA$ ) and the reddening corrected line emission intensities (in erg $\mathrm{cm}^{-2} \mathrm{~s}^{-1}$ ) are given in Table 1. Apparently there is no indication of any short-term modulation in the emission intensities, which show only a secular decline (see also Sect. 6). For this reason in Table 1 we have listed only one value per year for the emission intensity.

Most identifications are from the paper by Penston et al. (1983) but they have been checked also against the lists of $\mathrm{ADB}$ and $\mathrm{DF}$, and improved using recent lists of emission lines such as those of Kelly (1987), Morton (1991), Pradhan \& Peng (1995), and Williams (1995). We have changed some previous identifications and provided a tentative identification for some previously unidentified lines using our personal judgment but keeping in mind that, to a large extent, line identifications is more of an art than a science. In Table 1 we have marked with a bold character the previously unidentified lines that have been given an identification.

We recall that in $\mathrm{RR}$ Tel some information on the identification of a specific line comes from the line width itself because, as pointed out by Thackeray (1977) and Penston et al. (1983), there is a positive correlation between the line ionization level and the line width, as measured from the FWHM; this has helped us in some dubious cases. In this respect we point out that no appreciable variations in the line FWHMs are evident from our data for the $1978-1983$ time interval. It is also worth pointing out that the doublets of NIV] near $1485 \AA$ and of SiIII] near $1888 \AA$ both show a rather wide additional component in the emission profile with FWZI larger than $1.5 \AA$. This component is not evident in other lines of comparable ionization, e.g. in the SIV] and OIV] emissions near $1400 \AA$.

Incidentally, we want also to point out that, in our opinion, the very wide and shallow emission features (FWZI about $12 \AA$ ) underlying the strong lines of CIV $\lambda 1550$ and HeII $\lambda 1640$ (and partially NV $\lambda$ 1240) in the SWP 20246 long exposure spectrum are real and not an artifact associated with the severe overexposure in the line center. Such profiles are common in the high resolution spectra of CVs (Robinson et al. 1995; Friedjung et al. 1997) and their origin is commonly associated with material rotating at high velocity in the inner part of an accretion disk.

In the SWP 20246 spectrum we have found some additional (rather weak) features with respect to those reported by DB and by ADB. Since these features are not present in other spectra we have listed them separately in Table 3 together with tentative identifications and some notes.

\section{Comments on specific lines}

The apparent lack or weakness of some Si II lines, (e.g. $\lambda \lambda 1260.42,1304.37,1526.71$ ), while other lines (e.g. $\lambda$ 1533.44) are present is caused by i.s. re-absorption since the lower level of these lines is the zero-volt ground state. The $\lambda 1260.42$ emission is absorbed also by FeII(9) $1260.53 \AA$, while the $\lambda 1526.71$ emission is also affected by a reseaux mark. The $\lambda 1309.28$ line is present as a weak feature on the violet wing of the unidentified feature at 1309.32 A. The 1808.01 A zero-volt line is less affected by re-absorption since its $f$-factor is small.

Similarly, the OI triplet near $1300 \AA$ is affected by i.s. re-absorption in the 1302.17 line and by partial absorption by SiII $\lambda 1304.37$ in the $\lambda 04.86$ line. Also the $\lambda 1670.81$ emission line of Al II is affected by i.s. re-absorption and by a reseaux mark.

The presence of a few lines of SiI, as reported in ADB, is questionable; in our opinion it is just by chance coincidence because of the richness of the SiI spectrum. We prefer to ascribe the $\lambda 1698.6$ and $\lambda 1727.27$ features to SIII] $\lambda 1698.79$ and $\lambda 1722$ respectively, as in Penston et al. (1983), and Williams (1995). We leave as unidentified the rather strong feature observed at $1530.7 \AA$ that is not included in the lists of Penston (1983) or DF. We recall that an unidentified emission in the solar limb at $1530.89 \AA$ is reported by Burton \& Rydgeley (1970). We also leave as unidentified the feature at $1565.49 \AA ̊$.

A few lines identified as Fe II by DF, e.g., $\lambda \lambda$ 1360.20, $1776.61,1881.22,1884.11$ are very weak or absent in the FeII-rich spectrum of the symbiotic star $\mathrm{CH}$ Cyg. For 


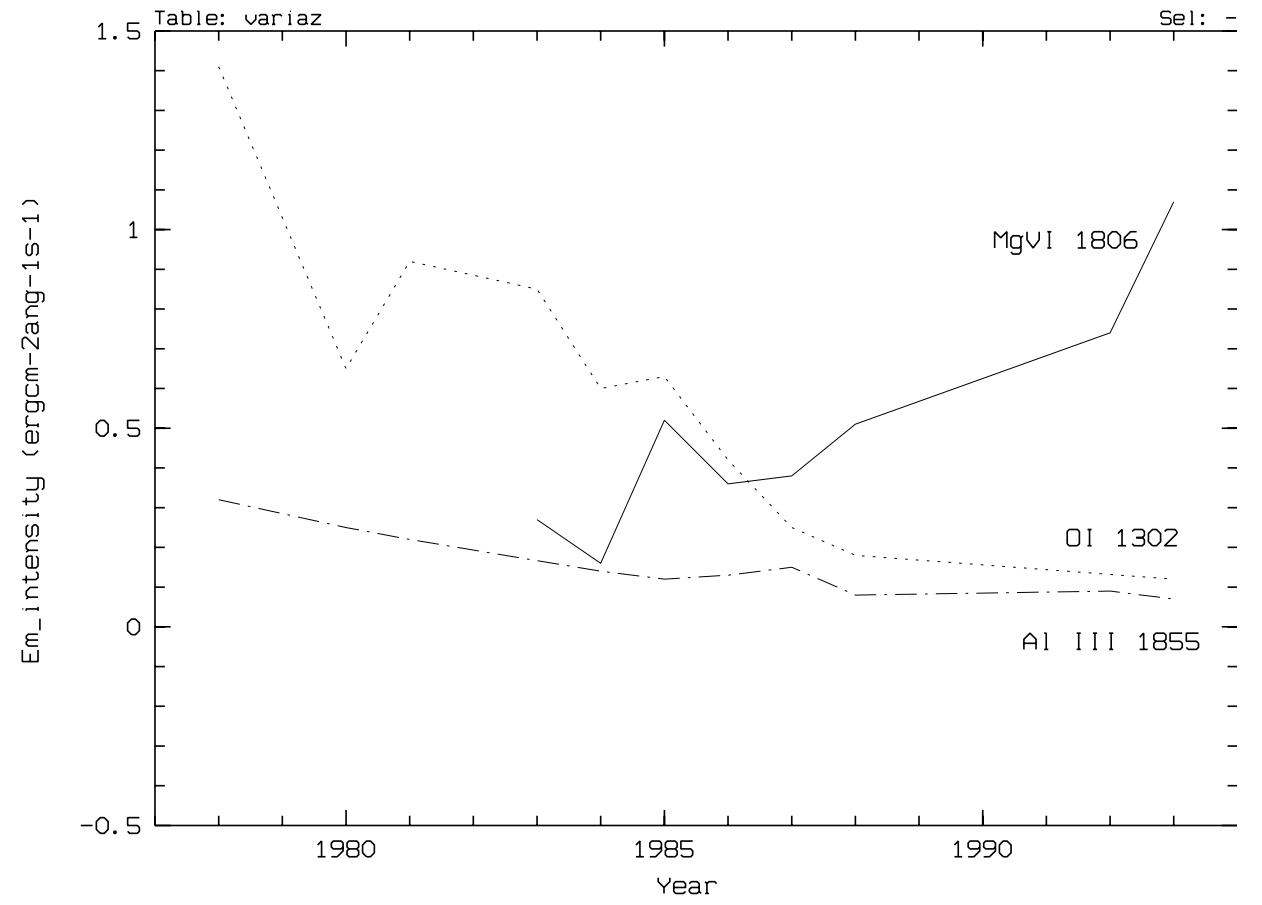

Fig. 1. The emission intensity variations from 1978 to 1993 for lines of different excitation
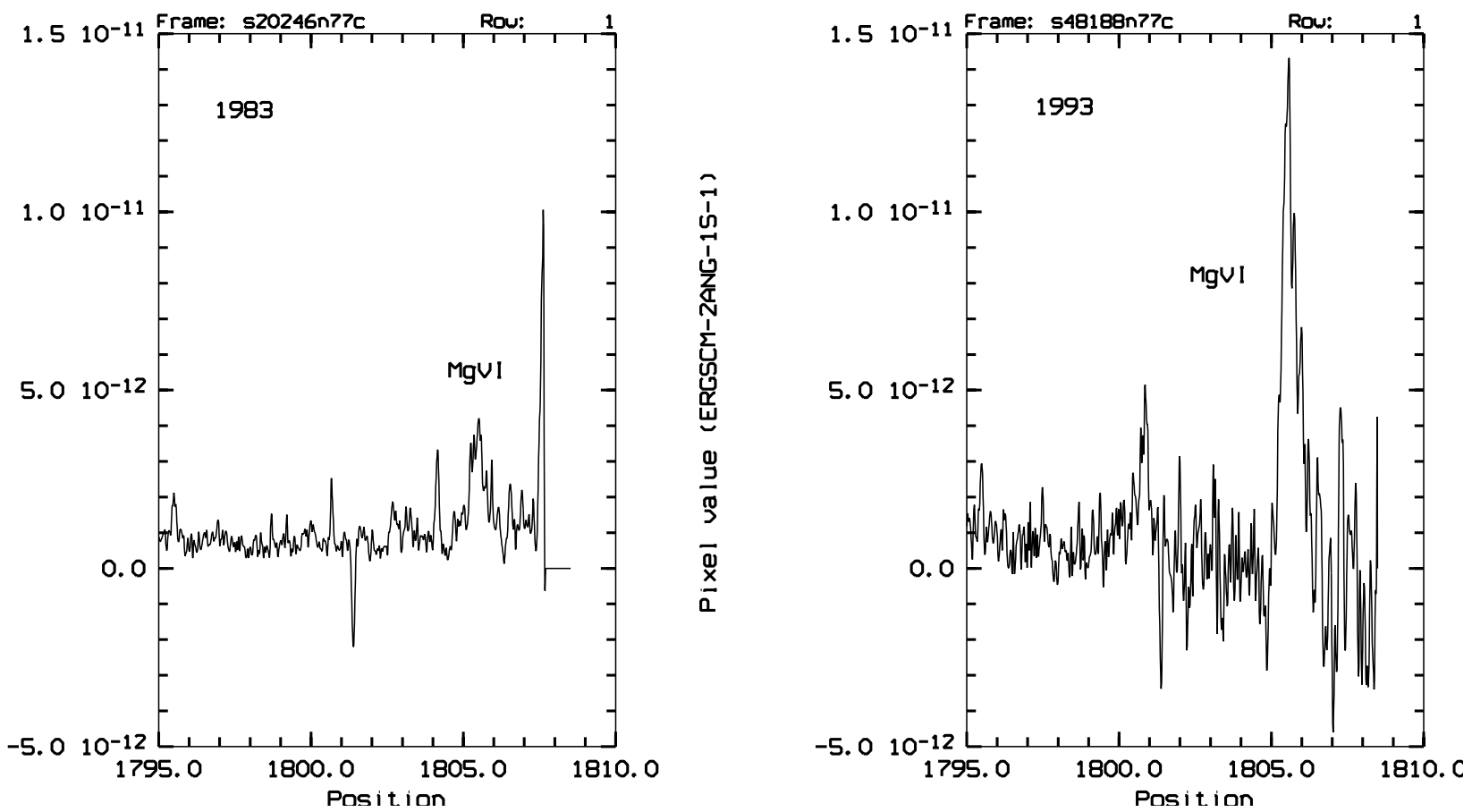

Fig. 2. The changes in the MgV line at $1805 \AA$ between 1978 and 1993 . Units in the $y$-axis are in $\operatorname{erg~cm}^{-2} \AA^{-1} \mathrm{~s}^{-1}$ 
this reason we consider these identifications as doubtful, although we are aware that different FeII excitation mechanisms in the two stars could explain this behavior. On the other hand, we have identified as FeII the two features at $\lambda \lambda 1869.26$ and 1872.41 $\AA$. These two lines are present in $\mathrm{CH}$ Cyg also and are excited by a fluorescent mechanism involving $\mathrm{Ly}_{\alpha}$. as pointed out by Johansson \& Jordan (1985) for late type stars. The line at $\lambda 1707.59$ is identified as FeII $\lambda 1708.24$ in ADB; we prefer OV $\lambda 07.95$ due to the large FWHM in the observed profile, thus indicating a high ionization emitter, and to the better consistency in the wavelengths.

It is worth to point out that, to the best of our knowledge, the newly found $\mathrm{Ne} \mathrm{V} \lambda 1145.60$ line (Table 2) is the feature at the shortest wavelength ever reported in an IUE spectrum.

- $\lambda 1189.8$ is identified as NI $\lambda 1190.0$ in ADB and as SIII (1) in Penston (1983), but, because of its large width we prefer Mg VI $\lambda$ 90.03, as in DF.

- $\lambda 1198.95$ is generally identified as SV $\lambda 1199.18$ but the sharpness of the profile would suggests, rather, a low ionization species.

- $\lambda 1324.24$ is generally ident. as $\mathrm{Mg} \mathrm{V}$, but the absence of the resonance line at $1293.9 \AA$ casts some doubts on this identification.

- $\lambda 1351.34$ previously unidentified, is attributed to $\mathrm{ClI}(2)$ 51.66, also in CH Cyg;

$--\lambda 1367.64$ prev. unid. is attributed to $\mathrm{CuII}(2) 67.95$ (Morton 1991), also in CH Cyg;

- $\lambda 1389.58$ prev. unid. is attributed to $\mathrm{CII}(1)$ 89.90, also in $\mathrm{CH}$ Cyg;

- $\lambda 1413.30$ is present in both orders but not included in the lists of ADB and DF. We attribute it to FeII (68) 13.71 ;

- $\lambda 1513.99$ prev. unid. is probably FeII $14.11+14.37$, also in $\mathrm{CH}$ Cyg;

- $\lambda 1619.35$ a rather wide feature, is attributed to NV 19.74 recombination line (Williams 1995). A possible contribution by CV $\lambda 1619.80$ seems unlikely because of the very high excitation $(380 \mathrm{eV})$ of this transition;

- $\lambda 1882.28$ absent in Penston (1983), not listed in ADB, unid. in DF; we attribute it to SiIII] 1882.65, the lowdensity companion to the SiIII] 1892.03 line. This is supported by the similarity in the two profiles;

- $\lambda$ 1910.29, previously unidentified, is attributed to FeII (124) 10.67, also in CH Cyg.

\section{The overall spectral variations}

In general, the observed decrease in the emission line intensities between 1978 and 1993 is of a factor larger than three and up to ten for the low-ionization lines (e.g., SilI, CII, OI, FeII, etc.) and of a factor between two and three for the medium-high excitation lines (e.g. OIV, NIV, CIII, etc..).
Instead, the high-ionization lines (e.g. MgV $\lambda$ 1324, OV $\lambda \lambda 1370,1844)$, which are all characterized by a broader profile, have generally maintained their original strength or have even increased it. Figure 1 is a plot of the changes with time in the emission intensity for the three kind of lines just mentioned.

It is worthwhile to report that the MgVI $\lambda 1190$ and $\lambda 1805$ lines, absent in Penston et al. (1983) list, have increased their strength from 1983 to 1993 by a factor about three (see Fig. 2). Also, a new emission feature observed at $1226.54 \AA$ has emerged in the 1993 spectrum. As pointed out by the referee the presence of a spurious emission feature (hot pixel or radiation hit) near $1227 \AA$ has been reported by Schoenberner \& Drilling (1985) and by Feibelman \& Bruhweiler (1990). However, the emission we observe is real because it is present in two different echelle orders and its rather wide profile is unlikely that of radiation hits or hot pixels. We identify it as Fe VII $\lambda 1226.65$, although there is no clear evidence of the other two Fe VII lines at $\lambda 1239.69$ and $\lambda 1332.38 \AA$.

The changes in the OI emissions are remarkable and deserve special comment. These lines are produced by the well known Bowen mechanism by which the accidental coincidence in wavelength between photons of $\mathrm{Ly}_{\beta}$ $\lambda 1025 \AA$ and the $2 \mathrm{p}^{4}{ }^{3} \mathrm{P} \rightarrow 3 \mathrm{~d}^{3} \mathrm{D}^{\mathrm{o}}$ transition of OI pumps this upper term. In the subsequent cascade the upper term $3 \mathrm{~s}{ }^{3} \mathrm{~S}^{\mathrm{o}}$ of the $\lambda 1300$ resonant triplet is excited and this results in the observed emission lines. Optical depth effects (and i.s. absorption) are severe in these lines and this results both in the presence of anomalous relative intensities in the triplet, and in the appearance of the semi-forbidden $\lambda 1641.3 \AA$ emission, a transition which has the same upper term as the $\lambda 1303$ triplet. In practice, the great optical depths in the $\lambda 1303$ photons has the effect of converting these "trapped" photons into $\lambda 1641.3$ photons that easily escape from the nebula. In $\mathrm{RR}$ Tel the changes in the $\lambda 1303$ triplet from 1978 to 1993 were dramatic: the total emission intensity decreased from $3.8810^{-11} \mathrm{erg} \mathrm{cm}^{-2} \mathrm{~s}^{-1}$ in 1978 to a very small value with an upper limit of $0.3310^{-11} \mathrm{erg} \mathrm{cm}^{-2} \mathrm{~s}^{-1}$ in 1993 (see Fig. 3). The semiforbidden $\lambda 1641.3$ emission, instead, decreased much less, from $0.9310^{-11} \mathrm{erg} \mathrm{cm}^{-2} \mathrm{~s}^{-1}$ in 1978 to $0.4310^{-11} \mathrm{erg} \mathrm{cm}^{-2} \mathrm{~s}^{-1}$ in 1993 , and this gives rise to a remarkable situation whereby of two transitions arising from the same upper level it is the one which is less favoured by the atomic probabilities that is actually stronger. These variations can be interpreted as evidence of higher optical depth in the OI resonance triplet, an indication of an increase in the column density of OI in the emitting region. However, the fact that the sum of the intensities of the $\lambda 1303$ triplet and of the $\lambda 1641.3$ line decreased significantly is an indication of a decrease in the fluorescent pumping efficiency also. Probably this occurs because fewer $\operatorname{Ly}_{\beta} \lambda 1025$ photons are available which, in turn, is an effect of the gradual 

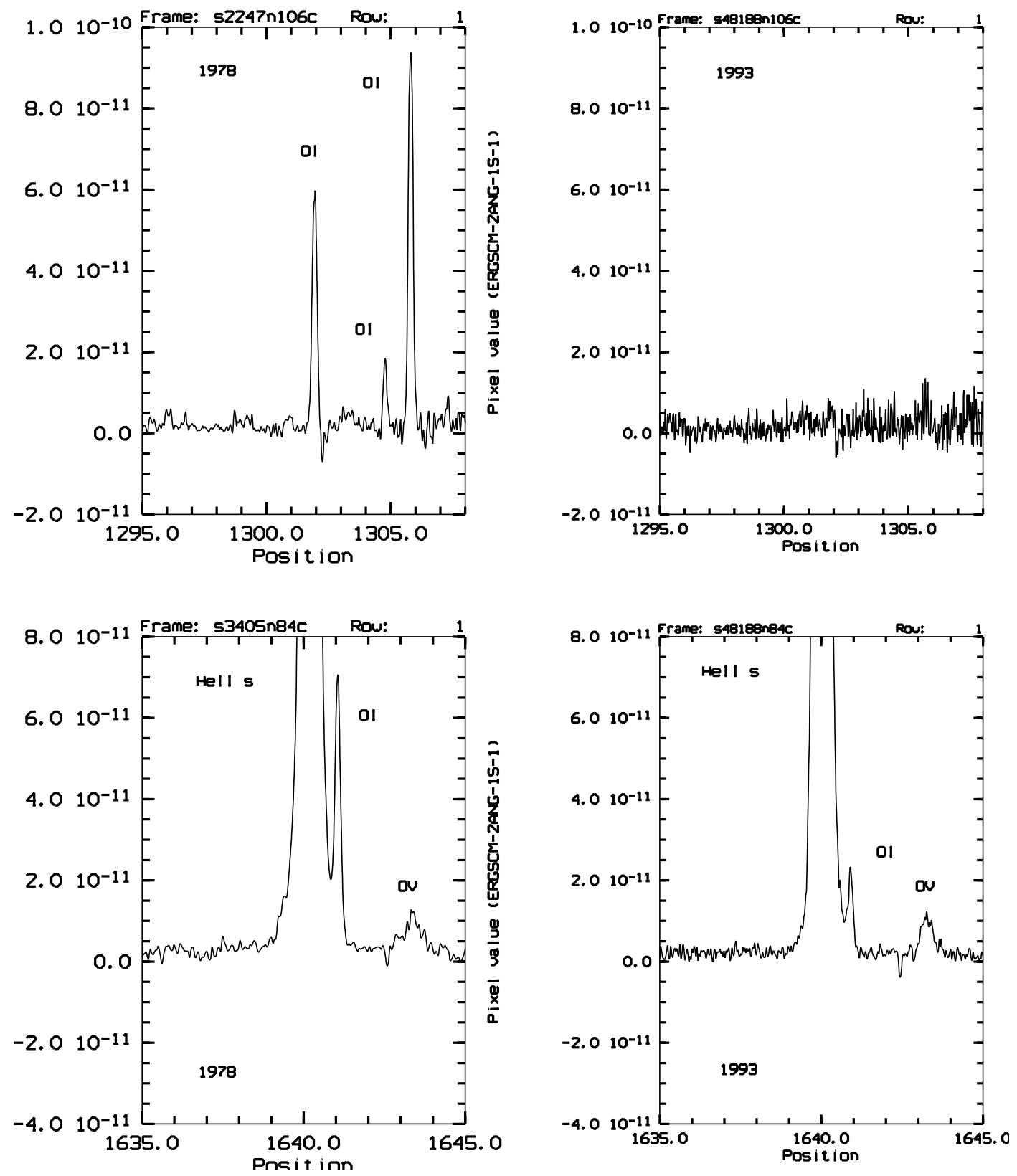

Fig. 3. The changes in the OI UV2 multiplet between 1978 and 1993

decline in the luminosity of the EUV ionizing source, as reported by Jordan et al. (1994).

Note added in proof: A very recent article by Crenshaw et al. (1996), appeared in NASA IUE Newsletter No. 56, gives a list of 39 high dispersion IUE artifacts. The agreement with our findings is fair: of the 42 such features we have found or confirmed in the range $1160-$ $1900 \AA$ (Table 3a) 17 are in common with the list of Crenshaw. Two artifacts (at 1474.13 and $1757.57 \AA$ ) of the 28 listed in $\mathrm{ADB}$ and not confirmed in our study are reported by Crenshaw et al. (1990).
Acknowledgements. A. Cassatella is gratefully acknowledged for having lent us an old fashioned tracing of the SWP 20246 spectrum. We thank S. Ferluga and R. Faraggiana for having allowed us to make use of the computing facilities of their workstations.

\section{References}

Aufdemberg J.P. (ADB) 1993, ApJS 87, 337

Burton W.M., Ridgeley A., 1970, Solar Phys. 14, 3

Cassatella A., Selvelli P.L., Ponz J.D., Gonzalez-Riestra R., Vogel M., 1994, A\&A 594, 602

Crenshaw D.M., Bruegman O.W., Norman D.J., 1990, PASP 102,463 
Doscheck G.A., Feibelman W.A. (DF) 1993, ApJS 87, 331

Espey B.R., et al., 1995, ApJ 454, L61

Feibelman W.A., Bruhweiler F.C., 1990, ApJ 357, 548

Friedjung M., Selvelli P.L., Cassatella A., 1997, A\&A 318, 204

Garhart M.P., 1992, The ESA IUE Newslett. 41, 44

Hack M., Selvelli P.L., 1982, A\&A 107, 200

Hayes M.A., Nussbaumer H., 1986, A\&A 161, 287

Johansson S., 1983, MNRAS 205, 71p

Johansson S., Jordan C., 1984, MNRAS 210, 239

Jordan C., 1979, Prog. in Atomic Spectroscopy. In: Hanle W. and Kleinpoppen H. (eds.). Plenum Press, Part B, p. 1453

Jordan S., Muerset U., Werner K., 1994, A\&A 283, 475

Kelly R.L., 1987, Atomic and Ionic Spectrum Lines Below 2000 A, Pt. 1, J. Phys. Chem. Ref. Data 16, Suppl. 1

Mathis J.S., 1990, ARA\&A 28, 37
Morton D.C., 1991, ApJS 77, 119

Penston M.V., et al., 1983, MNRAS 202, 833

Pradham A.K., Peng J., 1995, in "The Analysis of Emission lines", Williams R.W. and Livio M. (eds.). Cambridge Univ. Press, p. 8

Robinson E.L., Marsh T.R., Smak J.I., 1995, in: "Accretion Disks in Compact Stellar Systems", Wheeler J.C. (ed.) World Scientific, p. 75

Schoenberner D., Drilling J.S., 1985, ApJL 290, L49

Selvelli P.L., Gilmozzi R., Cassatella A., 1997 (in preparation) Thackeray A.D., 1977, Mem. R.A.S. 83, 1

Turnrose B.E., Thompson R.W., 1984, IUE Image Processing Information Manual Version 2.0, Computer Science Corporation/TM-84/6058

Williams R.E., 1995, PASP 107, 152 
Table 1. a) IUE Far-UV Spectrum from 1978 to 1982. FWHM and wawelengths are in $\AA$, emission intensities are in $10^{-11} \mathrm{erg} \mathrm{cm}^{-2} \mathrm{~s}^{-1} . s=$ saturated; $b l=$ blend; $b r=$ blemished by reseaux

\begin{tabular}{|c|c|c|c|c|c|c|c|c|c|c|c|}
\hline \multirow[b]{2}{*}{ element } & \multirow[b]{2}{*}{ mult. } & \multicolumn{2}{|c|}{ Wavelength } & \multicolumn{2}{|c|}{$\begin{array}{c}1978 \\
\mathrm{~S} 2247,180 \mathrm{~min} \\
a=\mathrm{S} 3407,1.5 \mathrm{~min} \\
b=\mathrm{S} 3405,36 \mathrm{~min}\end{array}$} & \multicolumn{2}{|c|}{$\begin{array}{c}1980 \\
\mathrm{~S} 10434,60 \mathrm{~min} \\
a=\mathrm{S} 9540,10 \mathrm{~min}\end{array}$} & \multicolumn{2}{|c|}{$\begin{array}{c}1981 \\
\mathrm{~S} 15229,44 \mathrm{~min} \\
a=\mathrm{S} 14727,25 \mathrm{~min} \\
b=\mathrm{S} 14230,10 \mathrm{~min}\end{array}$} & \multicolumn{2}{|c|}{$\begin{array}{c}1982 \\
\mathrm{~S} 18371,20 \mathrm{~min}\end{array}$} \\
\hline & & $\lambda_{\text {lab }}$ & $\lambda_{\text {obs }}$ & FWHM & Int. & FWHM & Tnt. & FWHM & Int. & FWHM & Tnt. \\
\hline CIII & 4 & 1174.93 & 74.68 & 0.19 & 0.53 & 0.15 & 0.87 & 025 & 0.66 & - & - \\
\hline CIII & 4 & 1175.59 & 75.36 & o.to & - & - & 0.59 & - & - & - & - \\
\hline$?$ & & & 86.49 & 0.24 & 0.31 & - & - & - & - & - & - \\
\hline$[\mathrm{SV}] ?$ & & 1199.18 & 98.95 & 0.19 & 1.51 & 0.22 & 1.39 & 0.17 & 1.07 & - & - \\
\hline SiIII & 2 & 1206.51 & 06.22 & 0.22 & 1.15 & 0.18 & 1.17 & 0.18 & 1.13 & - & 0.71 \\
\hline $\mathrm{OV}]$ & & 1218.41 & 18.15 & $0.24 \mathrm{~b}$ & $9.63 \mathrm{~b}$ & 0.24 & 9.76 & 0.26 & 9.40 & 0.45 & 7.61 \\
\hline NV & 1 & 1238.82 & 38.62 & $0.25 \mathrm{a}$ & $27.14 \mathrm{a}$ & $0.21 \mathrm{a}$ & $25.20 \mathrm{a}$ & $0.23 \mathrm{~b}$ & $26.84 \mathrm{~b}$ & 0.24 & 31.25 \\
\hline NV & 1 & 1242.80 & 42.65 & $0.21 \mathrm{a}$ & $13.67 \mathrm{a}$ & $0.22 \mathrm{a}$ & $15.20 \mathrm{a}$ & $0.25 \mathrm{~b}$ & $16.11 \mathrm{~b}$ & 0.21 & 15.40 \\
\hline CIII & 9 & 1247.38 & 47.11 & 0.34 & 0.14 & 0.29 & 0.37 & - & - & - & - \\
\hline$?$ & & & 49.81 & - & - & 0.26 & 0.18 & - & - & - & - \\
\hline SiII & 4 & $\begin{array}{r}1264.74 \\
+\quad 1265.00\end{array}$ & 64.66 & 0.19 & 0.08 & 0.34 & 0.18 & 0.27 & 0.20 & - & - \\
\hline OI & 2 & 1302.17 & 01.93 & 0.22 & 1.41 & 0.17 & $0.65 \mathrm{br}$ & 0.23 & $0.92 \mathrm{br}$ & - & - \\
\hline OI & 2 & 1304.86 & 04.69 & 0.17 & 0.30 & 0.12 & 0.39 & 0.11 & 0.12 & - & - \\
\hline OI & 2 & 1306.03 & 05.81 & 0.21 & 2.16 & 0.21 & 1.79 & 0.20 & 1.32 & 0.11 & 1.52 \\
\hline$?$ & & & 09.32 & 0.30 & 0.12 & - & - & - & - & - & - \\
\hline$[\mathrm{MgV}]$ & & 1324.45 & 24.24 & 0.32 & 0.33 & 0.29 & 0.50 & 0.24 & 0.34 & - & - \\
\hline CII & 1 & 1334.53 & 34.22 & 0.18 & 0.29 & 0.30 & 0.32 & 0.15 & 0.19 & - & - \\
\hline CII & 1 & 1335.66 & 35.40 & 0.29 & 0.45 & 0.19 & 0.31 & 0.22 & 0.37 & - & - \\
\hline OIV & & 1338.61 & 38.32 & 0.33 & 0.14 & 0.31 & 0.14 & 0.20 & 0.15 & 0.14 & 0.32 \\
\hline OIV & & 1343.51 & 43.24 & 0.21 & 0.32 & 0.13 & 0.38 & 0.24 & 0.43 & 0.17 & 0.81 \\
\hline NII & & 1345.08 & 44.67 & 0.12 & 0.11 & - & - & - & - & - & - \\
\hline FeII? & & 1360.23 & 59.87 & 0.21 & 0.16 & 0.14 & 0.12 & 0.15 & 0.12 & - & - \\
\hline [NaV] (Si III ?) & & 1365.25 & 65.08 & 0.17 & 0.13 & 0.23 & $0.07 \mathrm{br}$ & - & - & - & - \\
\hline OV & 7 & 1371.29 & 71.02 & 0.32 & 1.33 & 0.34 & 2.58 & 0.30 & 1.38 & $\mathrm{bl}$ & 1.9 \\
\hline SiIV & 1 & 1393.76 & 93.53 & $0.23 \mathrm{~b}$ & $6.64 \mathrm{~b}$ & 0.26 & 5.05 & 0.22 & 5.12 & 0.20 & 5.15 \\
\hline OIV] & & 1397.20 & 96.98 & 0.22 & 0.65 & 0.19 & 0.60 & 0.21 & 0.45 & 0.22 & 0.38 \\
\hline OIV] & & 1399.77 & 99.51 & $0.18 \mathrm{~b}$ & $1.81 \mathrm{~b}$ & 0.15 & 1.42 & 0.22 & 1.56 & $\mathrm{bl}$ & 1.10 \\
\hline OIV] & & 1401.16 & 00.89 & $0.22 \mathrm{~b}$ & $8.37 \mathrm{~b}$ & 0.20 & 7.33 & 0.23 & 7.45 & 0.21 & 7.15 \\
\hline SiIV & 1 & 1402.77 & 02.54 & $0.21 \mathrm{~b}$ & $2.96 \mathrm{~b}$ & 0.20 & 2.57 & 0.24 & 2.50 & 0.17 & 2.04 \\
\hline OIV] & & 1404.81 & 04.52 & $0.22 \mathrm{~b}$ & $4.73 \mathrm{~b}$ & 0.20 & 4.56 & 0.20 & 4.10 & 0.17 & 3.61 \\
\hline SIV] & & 1406.06 & 05.81 & 0.20 & 0.51 & 0.18 & 0.45 & 0.18 & 0.30 & 0.14 & 0.31 \\
\hline OIV] & & 1407.39 & 07.13 & 0.25 & 1.34 & 0.21 & 1.30 & 0.24 & 1.10 & $\mathrm{bl}$ & 1.17 \\
\hline NI & 10 & 1411.93 & 11.63 & 0.17 & 0.35 & 0.12 & 0.19 & 0.15 & 0.18 & - & - \\
\hline FeII & 68 & 1413.71 & 13.47 & 0.18 & 0.20 & - & - & 0.33 & 0.15 & - & - \\
\hline SIV] & & 1416.93 & 16.64 & 0.20 & 0.35 & 0.22 & 0.35 & 0.15 & 0.22 & - & - \\
\hline SIV] & & 1423.89 & 23.71 & - & - & 0.19 & 0.19 & - & - & - & - \\
\hline PIV] & & 1467.44 & 67.22 & 0.24 & 0.06 & - & - & - & - & - & - \\
\hline NIV] & & 1483.23 & 82.96 & 0.24 & 0.41 & 0.23 & 0.33 & 0.20 & 0.31 & - & - \\
\hline NIV] & & 1486.50 & 86.23 & $0.21 \mathrm{~b}$ & $9.49 \mathrm{~b}$ & $0.23 \mathrm{a}$ & $8.24 \mathrm{a}$ & 0.22 & 8.20 & 0.16 & 6.94 \\
\hline OV & 64 & 1506.76 & 06.58 & 0.25 & 0.17 & 0.35 & 0.18 & - & - & - & - \\
\hline SiII & 2 & 1533.43 & 33.13 & 0.34 & 0.24 & 0.67 & 0.21 & 0.29 & 0.42 & - & - \\
\hline CIV & 1 & 1548.20 & 48.01 & $0.27 \mathrm{a}$ & $66.55 \mathrm{a}$ & $\mathrm{s}$ & $\mathrm{s}$ & $\mathrm{s}$ & $\mathrm{s}$ & $\mathrm{s}$ & $\mathrm{s}$ \\
\hline CIV & 1 & 1550.77 & 50.59 & $0.26 \mathrm{a}$ & $35.40 \mathrm{a}$ & 0.28 & 32.8 & $0.29 \mathrm{~b}$ & $31.51 \mathrm{~b}$ & $\mathrm{~s}$ & $\mathrm{~s}$ \\
\hline$[\mathrm{NeV}]$ & & 1574.80 & 74.39 & 0.32 & 2.95 & 0.30 & 2.86 & 0.30 & 2.55 & 0.77 & 2.46 \\
\hline CIII & 12.03 & 1576.49 & 76.35 & 0.10 & 0.041 & - & - & - & - & - & - \\
\hline CIII & 12.03 & 1577.32 & 77.14 & 0.19 & 0.14 & - & - & - & - & - & - \\
\hline$[\mathrm{NeIV}]$ & & 1601.49 & 01.22 & $0.34 \mathrm{~b}$ & $1.88 \mathrm{~b}$ & 0.35 & 1.82 & 0.34 & 1.75 & 0.77 & 1.63 \\
\hline HeII & 12 & 1640.47 & 40.18 & $0.39 \mathrm{a}$ & $30.70 \mathrm{a}$ & $0.38 \mathrm{a}$ & $33.93 \mathrm{a}$ & $0.38 \mathrm{~b}$ & $30.39 \mathrm{~b}$ & $\mathrm{~s}$ & $\mathrm{~s}$ \\
\hline$[\mathrm{OI}]$ & & 1641.31 & 40.98 & bl $0.24 \mathrm{a}$ & bl $0.93 \mathrm{a}$ & 0.16 & 0.95 & - & - & - & - \\
\hline OV & 66 & 1643.62 & 43.27 & 0.46 & 0.20 & 0.45 & 0.44 & 0.49 & 0.31 & - & - \\
\hline OIII] & & 1660.80 & 60.50 & $0.21 \mathrm{~b}$ & $2.57 \mathrm{~b}$ & 0.21 & 2.35 & 0.22 & 2.11 & 0.15 & 1.59 \\
\hline OIII] & & 1666.15 & 65.84 & $0.20 \mathrm{a}$ & $7.60 \mathrm{a}$ & $0.23 \mathrm{a}$ & $6.46 \mathrm{a}$ & $0.22 \mathrm{a}$ & $5.95 \mathrm{a}$ & 0.21 & 5.57 \\
\hline $\mathrm{Al} \mathrm{II}$ & 2 & 1670.81 & 70.27 & 0.19 & 0.31 & - & - & - & - & - & - \\
\hline SIII]? & & 1698.61 & 98.20 & 0.32 & 0.06 & - & - & 0.14 & 0.08 & - & - \\
\hline FeII & 84 & 1708.24 & 08.01 & - & - & 0.65 & 0.12 & 0.46 & 0.10 & - & - \\
\hline$?$ & & & 10.01 & 0.40 & 0.04 & - & - & 0.17 & 0.03 & - & - \\
\hline FeII & & 1713.21 & 13.20 & - & - & 0.58 & 0.13 & - & - & - & - \\
\hline NIV & 7 & 1718.55 & 18.23 & 0.45 & 0.27 & $\mathrm{bl}$ & 0.30 & 0.47 & 0.30 & - & - \\
\hline SIII & & 1728.96 & 28.57 & 0.23 & 0.12 & - & - & 0.31 & 0.14 & - & - \\
\hline NI & 9 & 1742.72 & 42.47 & 0.16 & 0.03 & - & - & - & - & - & - \\
\hline NI & 9 & 1745.25 & 44.86 & 0.28 & 0.08 & - & - & - & - & - & - \\
\hline NIII] & & 1746.82 & 46.54 & 0.28 & 0.12 & 0.25 & 0.09 & 0.24 & 0.97 & - & - \\
\hline NIII] & & 1748.65 & 48.37 & 0.26 & 0.43 & 0.28 & 0.38 & 0.22 & 0.32 & 0.36 & 0.35 \\
\hline NIII] & & 1749.67 & 49.36 & $0.24 \mathrm{~b}$ & $1.77 \mathrm{~b}$ & 0.22 & 1.85 & 0.22 & 1.59 & 0.16 & 1.47 \\
\hline NIII] & & 1752.16 & 51.86 & $0.28 \mathrm{~b}$ & $0.72 \mathrm{~b}$ & 0.22 & 0.72 & 0.24 & 0.59 & - & - \\
\hline NIII] & & 1753.99 & 53.64 & 0.26 & 0.37 & 0.22 & 0.41 & 0.25 & 0.28 & - & - \\
\hline
\end{tabular}


Table 1. a) continued

\begin{tabular}{|c|c|c|c|c|c|c|c|c|c|c|c|}
\hline \multirow[b]{2}{*}{ element } & \multirow[b]{2}{*}{ mult. } & \multicolumn{2}{|c|}{ Wavelength } & \multicolumn{2}{|c|}{$\begin{array}{c}1978 \\
\mathrm{~S} 2247,180 \mathrm{~min} \\
a=\mathrm{S} 3407,1.5 \mathrm{~min} \\
b=\mathrm{S} 3405,36 \mathrm{~min}\end{array}$} & \multicolumn{2}{|c|}{$\begin{array}{c}1980 \\
\mathrm{~S} 10434,60 \mathrm{~min} \\
a=\mathrm{S} 9540,10 \mathrm{~min}\end{array}$} & \multicolumn{2}{|c|}{$\begin{array}{c}1981 \\
\mathrm{~S} 15229,44 \mathrm{~min} \\
a=\mathrm{S} 14727,25 \mathrm{~min} \\
b=\mathrm{S} 14230,10 \mathrm{~min}\end{array}$} & \multicolumn{2}{|c|}{$\begin{array}{c}1982 \\
\text { S18371, } 20 \text { min }\end{array}$} \\
\hline & & $\lambda_{\mathrm{lab}}$ & $\lambda_{\text {obs }}$ & FWHM & Int. & FWHM & Int. & FWHM & Int. & FWHM & Int. \\
\hline$?$ & & & 61.42 & 0.32 & 0.11 & - & - & 0.39 & 0.06 & 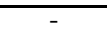 & - \\
\hline OIII & & 1768.33 & 67.93 & 0.27 & 0.03 & - & - & 0.21 & 0.03 & - & - \\
\hline FeII ? & & 1776.63 & 76.31 & 0.43 & 0.33 & 0.32 & 0.22 & 0.31 & 0.27 & - & - \\
\hline FeII & 191 & 1785.27 & 85.03 & 0.49 & 0.12 & - & - & - & - & - & - \\
\hline FeII & 191 & 1786.74 & 86.55 & 0.27 & 0.01 & - & - & - & - & - & - \\
\hline FeII & 191 & 1788.00 & 87.75 & 0.44 & 0.03 & - & - & - & - & - & - \\
\hline SiII & 1 & 1808.11 & 07.76 & 0.27 & 0.36 & 0.28 & 0.26 & 0.26 & 0.27 & 0.69 & 0.41 \\
\hline [NeIII] & & 1814.69 & 14.38 & 0.26 & 0.19 & 0.25 & 0.18 & 0.23 & 0.14 & - & - \\
\hline SiII & 1 & 1816.93 & 16.68 & $0.23 \mathrm{~b}$ & $0.61 \mathrm{~b}$ & 0.21 & 0.49 & 0.23 & 0.49 & 0.16 & 0.52 \\
\hline SiII & 1 & 1817.45 & 17.16 & 0.25 & 0.11 & 0.24 & 0.07 & 0.22 & 0.05 & - & - \\
\hline$?$ & & & 31.71 & 0.23 & 0.25 & & - & 0.22 & 0.21 & - & - \\
\hline OV & & 1844.42 & 43.92 & 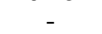 & 年 & 0.24 & 0.07 & - & . & - & - \\
\hline AlIII & 1 & 1854.72 & 54.44 & 0.31 & 0.32 & 0.30 & 0.25 & 0.35 & 0.22 & - & - \\
\hline AlIII & 1 & 1862.79 & 62.52 & 0.30 & 0.15 & 0.21 & 0.11 & 0.31 & 0.13 & - & - \\
\hline FeII & & 1869.53 & 69.26 & 0.28 & 0.07 & 0.25 & 0.08 & 0.42 & 0.07 & - & - \\
\hline FeII & & 1872.64 & 72.41 & 0.97 & 0.10 & 0.52 & 0.08 & 0.62 & 0.09 & - & - \\
\hline FeII? & & 1881.16 & 80.93 & 0.23 & 0.35 & 0.22 & 0.39 & 0.25 & 0.30 & 0.16 & 0.19 \\
\hline SiIII] & & 1882.69 & 82.30 & - & 0.04 & $0.16 \mathrm{a}$ & $0.02 \mathrm{a}$ & 1.5 & 0.08 & - & - \\
\hline FeII? & & 1884.11 & 83.81 & - & - & 0.21 & 0.53 & 0.21 & 0.41 & 0.23 & 0.37 \\
\hline SiIII] & & 1892.03 & 91.76 & $0.25 \mathrm{a}$ & $5.10 \mathrm{a}$ & $0.26 \mathrm{a}$ & $4.66 \mathrm{a}$ & $0.25 \mathrm{~b}$ & $5.08 \mathrm{~b}$ & $\mathrm{~s}$ & $\mathrm{~s}$ \\
\hline FeIII & 34 & 1895.56 & 95.17 & 0.26 & 0.04 & - & - & - & - & - & - \\
\hline
\end{tabular}

Table 1. b) IUE Far-UV Spectrum from 1983 to 1986

\begin{tabular}{|c|c|c|c|c|c|c|c|c|c|c|c|}
\hline \multirow[b]{2}{*}{ element } & \multirow[b]{2}{*}{ mult. } & \multicolumn{2}{|c|}{ Wavelength } & \multicolumn{2}{|c|}{$\begin{array}{c}1983 \\
\mathrm{~S} 20246,820 \mathrm{~min} \\
a=\mathrm{S} 20247,20 \mathrm{~min}\end{array}$} & \multicolumn{2}{|c|}{$\begin{array}{c}1984 \\
\mathrm{~S} 22531,40 \mathrm{~min}\end{array}$} & \multicolumn{2}{|c|}{$\begin{array}{c}1985 \\
\mathrm{~S} 27051,20 \mathrm{~min}\end{array}$} & \multicolumn{2}{|c|}{$\begin{array}{c}1986 \\
\mathrm{~S} 29535,220 \mathrm{~min} \\
a=\mathrm{S} 28741,20 \mathrm{~min}\end{array}$} \\
\hline & & $\lambda_{\text {lab }}$ & $\lambda_{\text {obs }}$ & FWHM & Int. & FWHM & Int. & FWHM & Int. & FWHM & Int. \\
\hline CIII & 4 & 1174.93 & 74.68 & 0.13 & 0.60 & - & - & - & - & 0.14 & 0.26 \\
\hline CIII & 4 & 1175.59 & 75.36 & 0.24 & 0.30 & - & - & - & - & - & 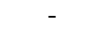 \\
\hline$?$ & & & 86.49 & $\mathrm{bl}$ & 0.40 & - & - & - & - & $\mathrm{bl}$ & 0.14 \\
\hline $\mathrm{MgVI}$ & & 1190.03 & 89.80 & 0.60 & 0.49 & bl & 0.26 & - & - & 0.19 & 0.58 \\
\hline$[\mathrm{SV}] ?$ & & 1199.18 & 98.95 & 0.21 & 0.80 & 0.54 & 1.17 & - & - & 0.24 & 0.73 \\
\hline SiIII & 2 & 1206.51 & 06.22 & 0.21 & 1.05 & 0.22 & 0.87 & 0.25 & 0.55 & $0.14 \mathrm{bl}$ & 0.56 \\
\hline $\mathrm{OV}]$ & & 1218.41 & 18.15 & $0.22 \mathrm{a}$ & $7.33 \mathrm{a}$ & 0.25 & 7.73 & 0.25 & 7.63 & $0.21 \mathrm{a}$ & $6.77 \mathrm{a}$ \\
\hline $\mathrm{NV}$ & 1 & 1238.82 & 38.62 & $0.21 \mathrm{a} . \mathrm{bl}$ & $31.04 \mathrm{a}$ & 0.22 & 27.66 & 0.22 & 26.55 & $0.23 \mathrm{a}$ & $26.60 \mathrm{a}$ \\
\hline $\mathrm{NV}$ & 1 & 1242.80 & 42.65 & $0.21 \mathrm{a}$ & $14.16 \mathrm{a}$ & 0.24 & 14.17 & 0.20 & 12.22 & $0.21 \mathrm{a}$ & $11.13 \mathrm{a}$ \\
\hline CIII & 9 & 1247.38 & 47.11 & 0.20 & 0.20 & - & - & - & - & - & - \\
\hline SiII & 4 & $\begin{array}{c}1264.74 \\
+1265.00\end{array}$ & 64.66 & $\mathrm{bl}$ & 0.11 & - & - & - & - & - & - \\
\hline FeII? & & 1265.57 & 65.33 & 0.19 & 0.06 & - & - & - & - & - & - \\
\hline OI & 2 & 1302.17 & 01.93 & $0.19 \mathrm{a}$ & $0.85 \mathrm{a}$ & 0.19 & 0.60 & 0.14 & 0.63 & 0.40 & 0.42 \\
\hline OI & 2 & 1304.86 & 04.69 & 0.13 & 0.18 & 0.37 & 0.17 & - & - & 0.12 & 0.18 \\
\hline OI & 2 & 1306.03 & 05.81 & bl. a & $0.97 \mathrm{a}$ & 0.23 & 1.00 & bl & 0.97 & 0.23 & 0.74 \\
\hline ? & & & 09.32 & bl & 0.17 & - & 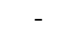 & - & - & 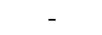 & . \\
\hline$[\mathrm{MgV}]$ & & 1324.45 & 24.24 & 0.27 & 0.52 & $\mathrm{bl}$ & 0.24 & - & - & 0.23 & 0.36 \\
\hline CII & 1 & 1334.53 & 34.22 & 0.16 & 0.20 & 0.20 & 0.17 & - & - & 0.18 & 0.11 \\
\hline CII & 1 & 1335.66 & 35.40 & 0.28 & 0.32 & 0.38 & 0.25 & 0.20 & 0.18 & 0.28 & 0.23 \\
\hline OIV & & 1338.61 & 38.32 & 0.24 & 0.08 & - & - & - & - & 0.18 & 0.09 \\
\hline OIV & & 1343.51 & 43.24 & 0.18 & 0.20 & - & - & - & - & 0.20 & 0.17 \\
\hline NII & & 1345.08 & 44.67 & 0.39 & 0.10 & 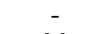 & - & - & - & 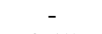 & - \\
\hline FeII ? & & 1360.23 & 59.87 & 0.11 & 0.14 & bl & 0.07 & - & - & 0.15 & 0.12 \\
\hline
\end{tabular}


Table 1. b) continued

\begin{tabular}{|c|c|c|c|c|c|c|c|c|c|c|c|}
\hline \multirow[b]{2}{*}{ element } & \multirow[b]{2}{*}{ mult. } & \multicolumn{2}{|c|}{ Wavelength } & \multicolumn{2}{|c|}{$\begin{array}{c}1983 \\
\mathrm{~S} 20246,820 \mathrm{~min} \\
a=\mathrm{S} 20247,20 \mathrm{~min}\end{array}$} & \multicolumn{2}{|c|}{$\begin{array}{c}1984 \\
\mathrm{~S} 22531,40 \mathrm{~min}\end{array}$} & \multicolumn{2}{|c|}{$\begin{array}{c}1985 \\
\mathrm{~S} 27051,20 \mathrm{~min}\end{array}$} & \multicolumn{2}{|c|}{$\begin{array}{c}1986 \\
\mathrm{~S} 29535,220 \mathrm{~min} \\
a=\mathrm{S} 28741,20 \mathrm{~min}\end{array}$} \\
\hline & & $\lambda_{\mathrm{lab}}$ & $\lambda_{\text {obs }}$ & FWHM & Int. & FWHM & Int. & FWHM & Int. & FWHM & \\
\hline$[\mathrm{NaV}]$ (Si III ?) & & 1365.25 & 65.08 & 0.26 & 0.11 & 0.19 & 0.12 & & & 0.37 & 0.10 \\
\hline $\mathrm{OV}$ & 7 & 1371.29 & 71.02 & $0.30 \mathrm{a}$ & $1.64 \mathrm{a}$ & 0.27 & 1.44 & 0.22 & 1.22 & 0.26 & 1.45 \\
\hline SiIV & 1 & 1393.76 & 93.53 & $0.21 \mathrm{a}$ & $4.45 \mathrm{a}$ & 0.19 & 4.21 & 0.22 & 3.78 & $0.24 \mathrm{a}$ & $3.07 \mathrm{a}$ \\
\hline OIV] & & 1397.20 & 96.98 & bl. a & $0.36 \mathrm{a}$ & 0.16 & 0.53 & $\mathrm{bl}$ & 0.77 & 0.22 & 0.45 \\
\hline OIV] & & 1399.77 & 99.51 & $0.15 \mathrm{a}$ & $0.90 \mathrm{a}$ & 0.22 & 0.98 & 0.13 & 1.11 & 0.19 & 0.85 \\
\hline OIV] & & 1401.16 & 00.89 & $0.19 \mathrm{a}$ & $6.67 \mathrm{a}$ & 0.19 & 6.38 & 0.20 & 5.46 & $0.19 \mathrm{a}$ & $5.46 \mathrm{a}$ \\
\hline SiIV & 1 & 1402.77 & 02.54 & $0.17 \mathrm{a}$ & $1.88 \mathrm{a}$ & 0.18 & 1.79 & 0.22 & 1.69 & $0.21 \mathrm{a}$ & $1.65 \mathrm{a}$ \\
\hline OIV] & & 1404.81 & 04.52 & $0.20 \mathrm{a}$ & $3.36 \mathrm{a}$ & 0.20 & 3.60 & 0.18 & 3.26 & $0.17 \mathrm{a}$ & $3.00 \mathrm{a}$ \\
\hline $\mathrm{SIV}]^{\top}$ & & 1406.06 & 05.81 & $0.18 \mathrm{a}$ & $0.12 \mathrm{a}$ & 0.20 & 0.33 & - & - & 0.19 & 0.30 \\
\hline OIV] & & 1407.39 & 07.13 & $0.19 \mathrm{a}$ & $0.92 \mathrm{a}$ & 0.19 & 0.91 & 0.20 & 0.82 & 0.20 & 0.80 \\
\hline NI & 10 & 1411.93 & 11.63 & 0.18 & 0.21 & - & - & - & - & 0.21 & 0.16 \\
\hline FeII & 68 & 1413.71 & 13.47 & 0.21 & 0.25 & - & - & - & - & 0.20 & 0.14 \\
\hline SIV] & & 1416.93 & 16.64 & 0.25 & 0.36 & 0.12 & 0.17 & - & - & 0.22 & 0.21 \\
\hline SIV] & & 1423.89 & 23.71 & 0.23 & 0.13 & - & 0.05 & - & - & - & - \\
\hline NIII (MgIV) & & 1470.68 & 70.34 & 0.39 & 0.07 & - & - & - & - & - & - \\
\hline NIV] & & 1483.23 & 82.96 & 0.22 & 0.29 & $\mathrm{bl}$ & 0.24 & - & - & $0.10 \mathrm{bl}$ & 0.20 \\
\hline NIV] & & 1486.50 & 86.23 & $0.18 \mathrm{a}$ & $6.36 \mathrm{a}$ & $0.19 \mathrm{br}$ & 6.83 & 0.17 & 6.25 & 0.18 br. a & $5.49 \mathrm{a}$ \\
\hline $\mathrm{OV}$ & 64 & 1506.76 & 06.58 & 0.22 & 0.17 & 0.40 & 0.24 & - & - & bl & 0.06 \\
\hline$?$ & & & 30.70 & 0.34 & 0.29 & - & - & - & - & - & - \\
\hline SiII & 2 & 1533.43 & 33.13 & 0.24 & 0.28 & - & - & - & - & $\mathrm{bl}$ & 0.13 \\
\hline CIV & 1 & 1548.20 & 48.01 & $\mathrm{~s}$ & $\mathrm{~s}$ & $\mathrm{~s}$ & $\mathrm{~s}$ & $\mathrm{~s}$ & $\mathrm{~s}$ & $\mathrm{~s}$ & $\mathrm{~s}$ \\
\hline CIV & 1 & 1550.77 & 50.59 & $\mathrm{~s}$ & $\mathrm{~s}$ & $\mathrm{~s}$ & $\mathrm{~s}$ & $\mathrm{~s}$ & $\mathrm{~s}$ & $\mathrm{~s}$ & $\mathrm{~s}$ \\
\hline$?$ & & & 65.49 & 0.28 & 0.10 & - & 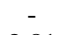 & - & - & - & - \\
\hline$[\mathrm{NeV}]$ & & 1574.80 & 74.39 & 0.22 a. bl & $1.89 \mathrm{a}$ & 0.27 & 2.31 & 0.31 & 2.01 & 0.29 & 2.00 \\
\hline$[\mathrm{NeIV}]$ & & 1601.49 & 01.22 & $0.30 \mathrm{a}$ & $1.49 \mathrm{a}$ & 0.33 & 1.48 & 0.17 & 1.32 & 0.30 & 1.26 \\
\hline NV? & & 1619.74 & 19.26 & 0.40 & 0.13 & 0.23 & 0.06 & - & - & - & - \\
\hline$?$ & & & 20.72 & 0.45 & 0.14 & - & - & - & - & - & - \\
\hline HeII & 12 & 1640.47 & 40.18 & $\mathrm{~s}$ & $\mathrm{~s}$ & $\mathrm{~s}$ & $\mathrm{~s}$ & $\mathrm{~s}$ & $\mathrm{~s}$ & $\mathrm{~s}$ & $\mathrm{~s}$ \\
\hline$[\mathrm{OI}]$ & & 1641.31 & 40.98 & $0.16 \mathrm{a}$ & $0.79 \mathrm{a}$ & 0.14 & 0.81 & 0.18 & 0.85 & $0.14 \mathrm{a}$ & $0.75 \mathrm{a}$ \\
\hline $\mathrm{OV}$ & 66 & 1643.62 & 43.27 & $0.10 \mathrm{a}$ & $0.26 \mathrm{a}$ & 0.30 & 0.25 & - & - & 0.46 & 0.40 \\
\hline OIII] & & 1660.80 & 60.50 & $0.22 \mathrm{a}$ & $1.69 \mathrm{a}$ & 0.21 & 1.68 & 0.21 & 1.62 & $0.19 \mathrm{a}$ & $1.49 \mathrm{a}$ \\
\hline OIII] & & 1666.15 & 65.84 & $0.19 \mathrm{a}$ & $5.28 \mathrm{a}$ & 0.20 & 5.03 & 0.19 & 4.53 & $0.21 \mathrm{a}$ & $4.59 \mathrm{a}$ \\
\hline$?$ & & & 82.71 & 0.10 & 0.05 & - & - & - & - & 0.15 & 0.03 \\
\hline SIII] ? & & 1698.61 & 98.20 & 0.49 & 0.09 & - & - & - & - & 0.17 & 0.05 \\
\hline $\mathrm{OV}$ & 67 & 1707.95 & 07.59 & 0.55 & 0.16 & 0.94 & 0.20 & 0.13 & 0.20 & $0.38 \mathrm{bl}$ & 0.11 \\
\hline$?$ & & & 10.01 & 0.14 & 0.03 & - & - & - & - & - & - \\
\hline S III & & 1713.12 & 12.77 & 0.35 & 0.07 & - & - & - & - & - & - \\
\hline NIV & 7 & 1718.55 & 18.23 & $\mathrm{bl}$ & 0.27 & $\mathrm{bl}$ & 0.24 & - & - & 0.51 & 0.22 \\
\hline$?$ & & & 25.02 & 0.20 & 0.05 & - & & - & - & - & - \\
\hline SIII & & 1728.96 & 28.57 & 0.23 & 0.11 & 0.15 & 0.05 & - & - & 0.20 & 0.08 \\
\hline NI & 9 & 1742.72 & 42.47 & 0.17 & 0.03 & - & - & - & - & - & - \\
\hline NI & 9 & 1745.25 & 44.86 & 0.22 & 0.06 & 0.12 & 0.05 & - & - & 0.16 & 0.02 \\
\hline NIII] & & 1746.82 & 46.54 & $0.22 \mathrm{a}$ & $0.10 \mathrm{a}$ & 0.55 & 0.07 & - & - & 0.28 & 0.07 \\
\hline NIII] & & 1748.65 & 48.37 & a. bl & $0.31 \mathrm{a}$ & 0.20 & 0.23 & $\mathrm{bl}$ & 0.32 & 0.18 & 0.20 \\
\hline NIII] & & 1749.67 & 49.36 & $0.21 \mathrm{a}$ & $1.43 \mathrm{a}$ & 0.21 & 1.24 & 0.22 & 1.41 & $0.20 \mathrm{a}$ & $1.15 \mathrm{a}$ \\
\hline NIII] & & 1752.16 & 51.86 & $0.23 \mathrm{a}$ & $0.63 \mathrm{a}$ & 0.18 & 0.58 & $0.20 \mathrm{bl}$ & 0.85 & $0.21 \mathrm{a}$ & $0.51 \mathrm{a}$ \\
\hline NIII] & & 1753.99 & 53.64 & a. bl & $0.27 \mathrm{a}$ & 0.22 & 0.22 & 0.22 & 0.24 & 0.23 & 0.22 \\
\hline$?$ & & & 61.42 & 0.30 & 0.08 & 0.43 & 0.12 & - & - & 0.25 & 0.06 \\
\hline OIII & & 1768.33 & 67.93 & 0.20 & 0.04 & 0.18 & 0.04 & - & - & 0.17 & 0.03 \\
\hline FeII ? & & 1776.63 & 76.31 & $\mathrm{~s}$ & $\mathrm{~s}$ & 0.18 & 0.19 & - & - & 0.39 & 0.21 \\
\hline FeII & 191 & 1785.27 & 85.03 & $\mathrm{bl}$ & 0.04 & - & - & - & - & - & - \\
\hline $\mathrm{MgVI}]$ & & 1805.96 & 05.47 & 0.49 & 0.27 & $\mathrm{bl}$ & 0.16 & 0.35 & 0.52 & 0.81 & 0.36 \\
\hline SiII & 1 & 1808.11 & 07.76 & $0.32 \mathrm{a}$ & $0.29 \mathrm{a}$ & 0.23 & 0.23 & 0.26 & 0.33 & 0.28 & 0.16 \\
\hline$[\mathrm{NeIII}]$ & & 1814.69 & 14.38 & $\mathrm{~s}$ & $\mathrm{~s}$ & 0.22 & 0.14 & $0.18 \mathrm{bl}$ & 0.13 & 0.28 & 0.10 \\
\hline SiII & 1 & 1816.93 & 16.68 & $0.21 \mathrm{a}$ & $0.44 \mathrm{a}$ & 0.23 & 0.41 & 0.22 & 0.42 & 0.22 & 0.40 \\
\hline SiII & 1 & 1817.45 & 17.16 & $\mathrm{~s}$ & $\mathrm{~s}$ & 0.23 & 0.07 & - & - & - & - \\
\hline$?$ & & & 31.71 & 0.29 & 0.11 & $0.17 \mathrm{bl}$ & 0.11 & - & - & 0.21 & 0.13 \\
\hline NI & 8 & 1836.74 & 36.25 & 0.29 & 0.01 & - & - & - & - & - & - \\
\hline $\mathrm{OV}$ & & 1844.42 & 43.92 & 0.54 & 0.10 & - & - & - & - & $0.34 \mathrm{bl}$ & 0.08 \\
\hline AlIII & 1 & 1854.72 & 54.44 & $\mathrm{~s}$ & $\mathrm{~s}$ & 0.27 & 0.14 & 0.33 & 0.12 & 0.29 & 0.13 \\
\hline$?$ & & & 59.96 & 0.54 & 0.03 & 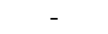 & 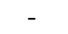 & - & - & - & . \\
\hline AlIII & 1 & 1862.79 & 62.52 & $\mathrm{~s}$ & $\mathrm{~s}$ & 0.32 & 0.08 & - & - & 0.32 & 0.06 \\
\hline FeII & & 1869.53 & 69.26 & 0.27 & 0.05 & 0.15 & 0.04 & - & - & 0.22 & 0.07 \\
\hline FeII & & 1872.64 & 72.41 & 0.28 & 0.06 & - & - & - & - & 0.19 & 0.07 \\
\hline FeII ? & & 1881.16 & 80.93 & $0.20 \mathrm{a}$ & $0.33 \mathrm{a}$ & 0.21 & 0.32 & 0.28 & 0.27 & 0.20 & 0.27 \\
\hline SiIII] & & 1882.69 & 82.30 & - & 0.10 & - & - & - & - & - & - \\
\hline FeII? & & 1884.11 & 83.81 & $0.23 \mathrm{a}$ & $0.45 \mathrm{a}$ & 0.20 & 0.43 & 0.18 & 0.51 & 0.21 & 0.39 \\
\hline SiIII] & & 1892.03 & 91.76 & $0.25 \mathrm{a}$ & $3.76 \mathrm{a}$ & $\mathrm{s}$ & $\mathrm{s}$ & 0.25 & 3.53 & $0.26 \mathrm{a}$ & $3.38 \mathrm{a}$ \\
\hline FeIII & 34 & 1895.56 & 95.17 & 0.32 & 0.04 & - & - & - & - & - & - \\
\hline
\end{tabular}


Table 1. c) IUE-Far UV Spectrum from 1987 to 1993

\begin{tabular}{|c|c|c|c|c|c|c|c|c|c|c|c|}
\hline \multirow[b]{2}{*}{ element } & \multirow[b]{2}{*}{ mult. } & \multicolumn{2}{|c|}{ Wavelength } & \multicolumn{2}{|c|}{$\begin{array}{c}1987 \\
\text { S } 31081,127 \text { min }\end{array}$} & \multicolumn{2}{|c|}{$\begin{array}{c}1988 \\
\mathrm{~S} 34702,435 \mathrm{~min} \\
a=\mathrm{S} 34005,20 \mathrm{~min}\end{array}$} & \multicolumn{2}{|c|}{$\begin{array}{c}1992 \\
\mathrm{~S} 46032,95 \mathrm{~min} \\
a=\mathrm{S} 45214,20 \mathrm{~min} \\
b=\mathrm{S} 46030,2 \mathrm{~min} \\
\end{array}$} & \multicolumn{2}{|c|}{$\begin{array}{c}1993 \\
\mathrm{~S} 48188,120 \mathrm{~min} \\
a=\mathrm{S} 48187,20 \mathrm{~min} \\
b=\mathrm{S} 47600,15 \mathrm{~min}\end{array}$} \\
\hline & & $\lambda_{\text {lab }}$ & $\lambda_{\text {obs }}$ & FWHM & Int. & FWHM & Int. & FWHM & & FWHM & Int. \\
\hline CIII & 4 & 1174.93 & 74.68 & - & - & - & - & - & 0.24 & & \\
\hline $\mathrm{MgVI}$ & & 1190.03 & 89.80 & - & - & - & - & - & - & 0.22 & 1.12 \\
\hline$[\mathrm{SV}] ?$ & & 1199.18 & 98.95 & 0.18 & 0.59 & 0.15 & 0.57 & - & - & - & 0.53 \\
\hline SiIII & 2 & 1206.51 & 06.22 & 0.20 & 0.51 & 0.16 & 0.37 & - & - & - & 0.35 \\
\hline $\mathrm{OV}]$ & & 1218.41 & 18.15 & 0.25 & 6.26 & $0.27 \mathrm{a}$ & $5.18 \mathrm{a}$ & 0.25 & 3.36 & 0.22 & 3.39 \\
\hline$?$ & & & 26.45 & - & - & - & - & - & - & 0.67 & 0.93 \\
\hline $\mathrm{NV}$ & 1 & 1238.82 & 38.62 & $\mathrm{~s}$ & $\mathrm{~s}$ & $0.22 \mathrm{a}$ & $17.25 \mathrm{a}$ & 0.21 & 15.83 & 0.24 & 15.10 \\
\hline NV & 1 & 1242.80 & 42.65 & $\mathrm{~s}$ & $\mathrm{~s}$ & $0.23 \mathrm{a}$ & $8.20 \mathrm{a}$ & $0.20 \mathrm{a}$ & $6.24 \mathrm{a}$ & $0.22 \mathrm{a}$ & $7.22 \mathrm{a}$ \\
\hline CIII & 9 & 1247.38 & 47.11 & $\mathrm{bl}$ & 0.16 & 0.16 & 0.09 & - & - & - & - \\
\hline$?$ & & & 49.81 & $\mathrm{bl}$ & 0.17 & 0.59 & 0.12 & - & - & 0.24 & 0.42 \\
\hline OI & 2 & 1302.17 & 01.93 & 0.38 & 0.25 & 0.22 & 0.18 & - & - & - & 0.12 \\
\hline OI & 2 & 1304.86 & 04.69 & 0.12 & 0.11 & - & - & - & - & - & - \\
\hline OI & 2 & 1306.03 & 05.81 & 0.26 & 0.66 & 0.20 & 0.31 & - & - & 0.22 & 0.21 \\
\hline$[\mathrm{MgV}]$ & & 1324.45 & 24.24 & 0.24 & 0.29 & 0.21 & 0.32 & 0.21 & 0.24 & 0.23 & 0.34 \\
\hline CII & 1 & 1334.53 & 34.22 & 0.51 & 0.20 & 0.35 & 0.08 & - & 0.04 & - & - \\
\hline CII & 1 & 1335.66 & 35.40 & 0.29 & 0.18 & 0.25 & 0.15 & - & 0.11 & 0.21 & 0.10 \\
\hline OIV & & 1338.61 & 38.32 & 0.18 & 0.05 & 0.16 & 0.05 & - & - & - & - \\
\hline OIV & & 1343.51 & 43.24 & $\mathrm{bl}$ & 0.10 & 0.17 & 0.13 & - & - & - & - \\
\hline FeII? & & 1360.23 & 59.87 & 0.19 & 0.11 & - & - & - & - & - & - \\
\hline [NaV] (SiIII ?) & & 1365.25 & 65.08 & 0.14 & 0.08 & 0.13 & 0.07 & - & - & 0.38 & 0.09 \\
\hline OV & 7 & 1371.29 & 71.02 & 0.28 & 1.50 & $\mathrm{~s}$ & $\mathrm{~s}$ & 0.27 & 1.27 & 0.29 & 1.24 \\
\hline SiIV & 1 & 1393.76 & 93.53 & $\mathrm{~s}$ & $\mathrm{~s}$ & $0.25 \mathrm{a}$ & $2.22 \mathrm{a}$ & 0.22 & 1.66 & 0.24 & 1.79 \\
\hline OIV] & & 1397.20 & 96.98 & 0.17 & 0.36 & 0.19 & 0.26 & 0.20 & 0.29 & 0.23 & 0.30 \\
\hline OIV] & & 1399.77 & 99.51 & 0.25 & 0.83 & 0.19 & 0.72 & 0.22 & 0.79 & 0.23 & 0.70 \\
\hline OIV] & & 1401.16 & 00.89 & $\mathrm{~s}$ & $\mathrm{~s}$ & $0.23 \mathrm{a}$ & $3.92 \mathrm{a}$ & 0.22 & 3.94 & 0.23 & 4.66 \\
\hline SiIV & 1 & 1402.77 & 02.54 & 0.23 & 1.57 & 0.24 & 1.50 & 0.25 & 0.89 & 0.24 & 0.99 \\
\hline OIV] & & 1404.81 & 04.52 & $\mathrm{~s}$ & $\mathrm{~s}$ & $0.23 \mathrm{a}$ & $1.96 \mathrm{a}$ & 0.20 & 2.01 & 0.20 & 2.25 \\
\hline SIV] & & 1406.06 & 05.81 & 0.18 & 0.23 & 0.18 & 0.21 & 0.37 & 0.18 & 0.19 & 0.20 \\
\hline OIV] & & 1407.39 & 07.13 & 0.22 & 0.82 & 0.21 & 0.59 & 0.22 & 0.56 & 0.22 & 0.61 \\
\hline NI & 10 & 1411.93 & 11.63 & 0.11 & 0.13 & 0.34 & 0.06 & - & - & - & - \\
\hline FeII & 68 & 1413.71 & 13.47 & 0.18 & 0.23 & - & - & - & - & - & - \\
\hline SIV] & & 1416.93 & 16.64 & 0.17 & 0.19 & 0.17 & 0.14 & 0.43 & 0.15 & 0.16 & 0.25 \\
\hline NIV] & & 1483.23 & 82.96 & $\mathrm{bl}$ & 0.23 & 0.33 & 0.22 & - & 0.23 & - & 0.16 \\
\hline NIV] & & 1486.50 & 86.23 & $\mathrm{~s}$ & $\mathrm{~s}$ & $0.19 \mathrm{a}$ & $3.76 \mathrm{a}$ & 0.21 & 3.63 & $0.18 \mathrm{a}$ & $3.42 \mathrm{a}$ \\
\hline OV & & 1506.76 & 06.58 & - & - & - & 0.08 & - & - & - & - \\
\hline SiII & 2 & 1533.43 & 33.13 & - & - & 0.16 & 0.06 & - & - & - & - \\
\hline CIV & 1 & 1548.20 & 48.01 & $\mathrm{~s}$ & $\mathrm{~s}$ & $\mathrm{~s}$ & $\mathrm{~s}$ & $0.29 \mathrm{a}$ & $27.48 \mathrm{a}$ & $0.26 \mathrm{~b}$ & $16.31 \mathrm{~b}$ \\
\hline CIV & 1 & 1550.77 & 50.59 & $\mathrm{~s}$ & $\mathrm{~s}$ & $\mathrm{~s}$ & $\mathrm{~s}$ & $0.26 \mathrm{a}$ & $15.58 \mathrm{a}$ & $0.26 \mathrm{a}$ & $14.38 \mathrm{a}$ \\
\hline$?$ & & & 65.49 & - & - & - & - & - & - & 0.27 & 0.10 \\
\hline$[\mathrm{NeV}]$ & & 1574.80 & 74.39 & 0.28 & 2.01 & $\mathrm{bl}$ & $1.53 \mathrm{a}$ & 0.29 & 1.43 & 0.29 & 1.67 \\
\hline$[\mathrm{NeIV}]$ & & 1601.49 & 01.22 & 0.31 & 1.34 & 0.72 & $1.34 \mathrm{a}$ & 0.31 & 0.97 & 0.30 & 0.95 \\
\hline HeII & 12 & 1640.47 & 40.18 & $\mathrm{~s}$ & $\mathrm{~s}$ & $\mathrm{~s}$ & $\mathrm{~s}$ & $0.36 \mathrm{~b}$ & $14.41 \mathrm{~b}$ & $0.36 \mathrm{~b}$ & $15.75 \mathrm{~b}$ \\
\hline [OI] & & 1641.31 & 40.98 & 0.17 & 0.60 & $\mathrm{bl}$ & $\mathrm{bl}$ & 0.12 & 0.35 & 0.16 & 0.43 \\
\hline $\mathrm{OV}$ & & 1643.62 & 43.27 & 0.36 & 0.29 & 0.41 & 0.39 & 0.55 & 0.36 & 0.41 & 0.38 \\
\hline OIII] & & 1660.80 & 60.50 & $\mathrm{~s}$ & $\mathrm{~s}$ & $0.19 \mathrm{a}$ & $1.17 \mathrm{a}$ & 0.23 & 0.88 & 0.23 & 1.01 \\
\hline OIII] & & 1666.15 & 65.84 & $\mathrm{~s}$ & $\mathrm{~s}$ & $0.22 \mathrm{a}$ & $3.16 \mathrm{a}$ & 0.23 & 2.56 & $0.21 \mathrm{a}$ & $2.90 \mathrm{a}$ \\
\hline SIII]? & & 1698.61 & 98.20 & - & - & 0.18 & 0.05 & - & - & - & - \\
\hline $\mathrm{OV}$ & 67 & 1707.95 & 07.59 & 0.53 & 0.14 & 0.37 & 0.10 & - & 0.08 & 0.36 & 0.10 \\
\hline NIV & 7 & 1718.55 & 18.23 & 0.22 & 0.19 & 0.41 & 0.19 & 0.69 & 0.18 & 0.41 & 0.24 \\
\hline SIII & & 1728.96 & 28.57 & 0.18 & 0.08 & 0.15 & 0.07 & 0.21 & 0.11 & 0.26 & 0.09 \\
\hline NI & 9 & 1742.72 & 42.47 & - & - & 0.56 & 0.01 & - & - & - & - \\
\hline NI & 9 & 1745.25 & 44.86 & 0.54 & 0.05 & $\mathrm{bl}$ & 0.03 & - & - & - & - \\
\hline NIII] & & 1746.82 & 46.54 & 0.28 & 0.05 & 0.36 & 0.06 & 0.11 & 0.04 & 0.47 & 0.04 \\
\hline NIII] & & 1748.65 & 48.37 & 0.21 & 0.20 & 0.22 & 0.17 & 0.25 & 0.16 & 0.23 & 0.15 \\
\hline NIII] & & 1749.67 & 49.36 & 0.24 & 1.08 & $0.27 \mathrm{a}$ & $1.11 \mathrm{a}$ & 0.21 & 0.77 & 0.24 & 0.87 \\
\hline NIII] & & 1752.16 & 51.86 & 0.20 & 0.40 & $0.19 \mathrm{a}$ & $0.40 \mathrm{a}$ & 0.22 & 0.38 & 0.27 & 0.33 \\
\hline NIII] & & 1753.99 & 53.64 & 0.21 & 0.20 & 0.23 & 0.15 & 0.22 & 0.14 & 0.20 & 0.13 \\
\hline$?$ & & & 61.42 & $\mathrm{bl}$ & 0.15 & 0.21 & 0.05 & 0.26 & 0.05 & 0.22 & 0.04 \\
\hline OIII & & 1768.33 & 67.93 & - & 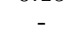 & 0.21 & 0.02 & - & - & - & - \\
\hline FeII? & & 1776.63 & 76.31 & 0.54 & 0.24 & 0.14 & 0.15 & 0.40 & 0.08 & 0.14 & 0.18 \\
\hline$[\mathrm{MgVI}]$ & & 1805.96 & 05.47 & 0.62 & 0.38 & 0.65 & 0.51 & 0.60 & 0.74 & 0.64 & 1.07 \\
\hline SiII & 1 & 1808.11 & 07.76 & 0.29 & 0.19 & 0.32 & 0.11 & 0.32 & 0.07 & 0.39 & 0.09 \\
\hline$[\mathrm{NeIII}]$ & & 1814.69 & 14.38 & 0.25 & 0.11 & 0.20 & 0.08 & 0.19 & 0.06 & 0.20 & 0.08 \\
\hline SiII & 1 & 1816.93 & 16.68 & 0.24 & 0.30 & $\mathrm{~s}$ & $\mathrm{~s}$ & 0.26 & 0.13 & 0.30 & 0.17 \\
\hline SiII & 1 & 1817.45 & 17.16 & 0.22 & 0.06 & $\mathrm{~s}$ & $\mathrm{~s}$ & - & - & - & - \\
\hline$?$ & & & 31.71 & 0.22 & 0.08 & 0.16 & 0.06 & 0.19 & 0.07 & 0.21 & 0.07 \\
\hline OV & & 1844.42 & 43.92 & 0.67 & 0.12 & 0.45 & 0.09 & 0.38 & 0.11 & 0.54 & 0.16 \\
\hline
\end{tabular}


Table 1. c) continued

\begin{tabular}{|c|c|c|c|c|c|c|c|c|c|c|c|}
\hline \multirow[b]{2}{*}{ element } & \multirow[b]{2}{*}{ mult. } & \multicolumn{2}{|c|}{ Wavelength } & \multicolumn{2}{|c|}{$\begin{array}{c}1987 \\
\text { S } 31081,127 \text { min }\end{array}$} & \multicolumn{2}{|c|}{$\begin{array}{c}1988 \\
\mathrm{~S} 34702,435 \mathrm{~min} \\
a=\mathrm{S} 34005,20 \mathrm{~min}\end{array}$} & \multicolumn{2}{|c|}{$\begin{array}{c}1992 \\
\mathrm{~S} 46032,95 \mathrm{~min} \\
a=\mathrm{S} 45214,20 \mathrm{~min} \\
b=\mathrm{S} 46030,2 \mathrm{~min}\end{array}$} & \multicolumn{2}{|c|}{$\begin{array}{c}1993 \\
\mathrm{~S} 48188,120 \mathrm{~min} \\
a=\mathrm{S} 48187,20 \mathrm{~min} \\
b=\mathrm{S} 47600,15 \mathrm{~min}\end{array}$} \\
\hline & & $\lambda_{\text {lab }}$ & $\lambda_{\text {obs }}$ & FWHM & Int. & FWHM & Int. & FWHM & Int. & FWHM & Int. \\
\hline AlIII & 1 & 1854.72 & 54.44 & 0.34 & 0.15 & 0.33 & 0.08 & 0.35 & 0.09 & 0.56 & 0.07 \\
\hline$?$ & & & 59.96 & - & - & 0.65 & 0.02 & - & - & - & - \\
\hline AlIII & 1 & 1862.79 & 62.52 & 035 & 0.06 & 0.22 & 0.04 & - & - & - & - \\
\hline FeII & & 1869.53 & 69.26 & 0.21 & 0.04 & 0.15 & 0.02 & - & - & 0.55 & 0.06 \\
\hline FeII & & 1872.64 & 72.41 & 0.12 & 0.05 & 0.15 & 0.02 & . & - & - & - \\
\hline FeII ? & & 1881.16 & 80.93 & 0.21 & 0.26 & 0.21 & 0.20 & 0.18 & 0.20 & 0.22 & 0.23 \\
\hline FeII ? & & 1884.11 & 83.81 & 0.18 & 0.35 & $0.23 \mathrm{a}$ & $0.37 \mathrm{a}$ & 0.17 & 0.31 & 0.21 & 0.35 \\
\hline SiIII] & & 1892.03 & 91.76 & $\mathrm{~s}$ & $\mathrm{~s}$ & $0.27 \mathrm{a}$ & $2.25 \mathrm{a}$ & $0.27 \mathrm{a}$ & $1.74 \mathrm{a}$ & $0.26 \mathrm{a}$ & $1.76 \mathrm{a}$ \\
\hline
\end{tabular}

Table 2. Additional lines present in SWP 20246 only

\begin{tabular}{||lc|cc|cc|l||}
\hline \hline & & \multicolumn{2}{|c|}{ Wavelength } & & \\
element & mult. & $\lambda_{\text {lab }}$ & $\lambda_{\text {obs }}$ & FWHM & Intensity & \multicolumn{1}{||}{ Notes } \\
\hline NeV & & 1145.60 & 45.30 & 0.24 & - & Jordan (1973) \\
CIII & & 1296.33 & 96.00 & 0.26 & 0.08 & Kelly (1987) \\
$?$ & & & 1307.00 & 0.32 & 0.08 & \\
NIII & & 1387.30 & 86.90 & 0.28 & 0.10 & Kelly (1987) \\
FeII & 69 & 1413.70 & 13.30 & 0.12 & 0.28 & Also in CH Cyg \\
Ni II & 6 & 1510.85 & 10.40 & 0.26 & 0.04 & Also in CH Cyg \\
SiII & 2 & 1526.71 & 26.40 & - & $>0.08$ & reabsorbed \\
$?$ & & & 1562.20 & 0.12 & 0.04 & \\
$?$ & & & 1778.30 & - & 0.03 & \\
$?$ & & & 1778.70 & 0.22 & 0.05 & \\
$?$ & & & 1781.10 & 0.23 & 0.03 & \\
NIII & & 1835.31 & 35.20 & 0.20 & 0.02 & Kelly (1987) \\
OV & UV75 & 1845.63 & 45.30 & 0.32 & $>0.03$ & \\
$?$ & & & 1899.80 & - & $>0.03$ & blend \\
\hline \hline
\end{tabular}

Table 3. Spectral artifacts in SWP 20246

\begin{tabular}{||c|cc||}
\hline \hline $\begin{array}{c}\text { Table 3a } \\
\text { Confirmed (or likely) spectral } \\
\text { artifacts from ADB }\end{array}$ & \multicolumn{2}{c||}{$\begin{array}{c}\text { Table 3b } \\
\text { Additional artifacts found } \\
\text { in this study }\end{array}$} \\
\hline$\lambda$ as in ADB & \multicolumn{2}{|c||}{$\lambda_{\text {obs }}$} \\
\hline 1216.35 & 1160.0 & 1583.9 \\
1281.62 & 1165.9 & 1629.8 \\
1298.48 & 1266.9. & 1691.1 \\
1504.94 & 1287.9. & 1702.7 \\
1536.84 & 1288.2 & 1706.9 \\
1603.40 & 1288.5 & 1710.0 \\
1603.92 & 1288.8 & 1729.0 \\
1604.37 & 1315.7 & 1755.6 \\
1692.91 & 1381.7 & 1800.0 \\
1718.62 & 1453.7 & 1825.1 \\
1725.77 & 1454.1 & \\
1762.21 & 1454.9 & \\
1794.07 & 1460.7 & \\
1795.38 & 1487.8 & \\
1809.93 & 1500.9 & \\
1845.27 & 1573.0 & \\
\hline \hline
\end{tabular}

